\title{
ESPAÇOS PARA CRIANÇAS E IDOSOS: ESTUDO DA PRAÇA ARGILANO DÁRIO, VILA VELHA-ES
}

\author{
RAMOS, Larissa Letícia Andara \\ Universidade Vila Velha, e-mail: Larissa.ramos@uvv.br \\ PAULA, Rhaquel Souza de \\ Universidade Vila Velha, e-mail: rhaqueldepaula@gmail.com \\ VIVAS, Paula Guimarães \\ Universidade Vila Velha, e-mail: paulaguimaraesv@gmail.com \\ JESUS, Luciana Aparecida Netto de \\ Universidade Federal de Espírito Santo, e-mail: Luciana.njesus@gmail.com
}

\begin{abstract}
RESUMO
Na busca por cidades contemporâneas mais inclusivas e por um equilíbrio entre sociedade, natureza e espaço urbano, é apropriado considerar, no planejamento urbano, espaços acolhedores para as crianças, mas também espaços onde convivem todas as gerações, onde umas aprendem e se enriquecem com as outras, potencializando o ciclo da vivência urbana. A partir desse contexto, o presente trabalho tem como objetivo refletir sobre a inclusão de crianças e idosos em espaços livres de uso público, tendo como estudo de caso a praça Argilano Dario, situada em área de vulnerabilidade urbana do município de Vila Velha-ES. O trabalho foi desenvolvido em quatro etapas metodológicas: Contextualização do tema; Estudo de exemplos de projetos; Construção dos indicadores e Análise do espaço. A análise apresentada, além de fornecer reflexões sobre a qualidade dos espaços para idosos e crianças e os desafios para a construção de cidades inclusiva, indica ainda que a praça, apesar de situada em bairro residencial, não atende as reais necessidades desse público.
\end{abstract}

Palavras-chave: Espaço público, Inclusão, Idosos, Crianças.

\begin{abstract}
In the search for more inclusive contemporary cities and a balance between society, nature and urban space, it is appropriate to consider, in urban planning, cozy spaces for children, but also spaces where all generations live, where some learn and enrich themselves with others, enhancing the cycle of urban living. From this context, the present study aims to reflect on the inclusion of children and elderly people in free spaces for public use, having as a case study the Argilano Dario square, located in an area of urban vulnerability in the municipality of Vila VelhaES. The work was developed in four methodological stages: Contextualization of the theme; Study of project examples; Construction of indicators and Analysis of space. The analysis presented, besides providing reflections on the quality of spaces for the elderly and children and the challenges for the construction of inclusive cities, also indicates that the square, although located in a residential neighborhood, does not meet the real needs of this public
\end{abstract}

Keywords: Public Space, Inclusion, Older, Children

\section{INTRODUÇÃO}

Os espaços públicos são essenciais para o bem-estar humano, contribuindo diretamente para a qualidade ambiental e urbana. São lugares onde ocorrem trocas de vivências e experiências - por meio da integração de diversas

RAMOS, L. L. A.; PAULA, R. S.; VIVAS, P. G.; JESUS, L. A. N. Espaço para crianças e idosos: estudo da Praça Argilano Dario, Vila Velha - ES. In: SIMPÓSIO BRASILEIRO DE QUALIDADE DO PROJETO NO AMBIENTE CONSTRUÍDO, 6., 2019, Uberlândia. Anais... Uberlândia: PPGAU/FAUeD/UFU, 2019. p. 88-96. DOl https://doi.org/10.14393/sbqp19009. 
gerações, crenças e classes sociais - favorecendo a sociabilidade e estruturando a identidade de uma comunidade, fomentando também a sensação de pertencimento (GEHL, 2010).

Tendo em visto a atual cenário de envelhecimento populacional preocupar-se com a inclusão de idosos nos espaços públicos torna-se uma tarefa indispensável. A terceira idade faz parte do segmento excluído da sociedade, o que é visível no preconceito estabelecido nas relações sociais, em que a velhice é vista como uma fase de falência e perda de motivação (CORREA, 2016). Os desafios enfrentados pelos idosos são considerados barreiras físicas e sociais, que comprometem seu acesso ao espaço público urbano e ainda delimitam o(s) lugar(es) que devem ocupar e a maneira como devem fazê-lo, principalmente nos tópicos de acessibilidade e sociabilidade.

Atualmente, muito se tem discutido acerca da terceira idade ativa, em que ações como conhecer novos lugares e desenvolver atividades de lazer ao ar livre são incentivadas, trazendo melhorias significativas para bem-estar físico e mental do idoso. Dessa forma investigar como os espaços públicos devem estar preparados para atender a população idosa, tornou-se temática de estudos e análises, realizados por diversos profissionais e estudantes da área de arquitetura e urbanismo.

O ambiente urbano também tem a capacidade de transformar e/ou moldar o indivíduo desde a sua infância, caracteriza-se como um período de construção social fundamental para o desenvolvimento da criança. Em função disso, os espaços públicos tornam-se um dos primeiros contatos do público infantil para com a cidade, onde estabelecem relações sociais e praticam suas vivências.

Os espaços públicos são vistos como ambientes de liberdade e diversão para as crianças, pois é na brincadeira que elas encontram espaço para o seu desenvolvimento psíquico e físico. A ausência desses espaços pode influenciar negativamente no desenvolvimento infantil, fazendo com que as crianças não utilizem de todos os seus potenciais, passíveis de se tornarem adultos não totalmente saudáveis e socialmente integrados.

Na busca por cidades contemporâneas mais inclusivas e por um equilíbrio entre sociedade, natureza e espaço urbano, é apropriado considerar, no planejamento urbano, espaços acolhedores para as crianças, mas também espaços onde convivem todas as gerações, onde umas aprendem e se enriquecem com as outras, potencializando o ciclo da vivência urbana.

Nesse contexto, tendo em vista a busca por uma cidade mais inclusiva e de espaços acolhedores para as gerações, a presente pesquisa analisa a qualidade dos espaços para crianças e para idosos na cidade, tendo como objeto de estudo a praça Argilano Dario no munícipio de Vila Velha - ES. A discussão é realizada conforme parâmetros estudados pelo grupo de pesquisa "Paisagem Urbana e Inclusão" da Universidade Vila Velha e Universidade Federal do Espírito Santo e que busca, a partir da avaliação de praças, discutir as diferenças de tratamento do espaço público na região metropolitana de Vitória. 


\section{METODOLOGIA}

Para atingir o objetivo proposto, foram realizadas pesquisas de dissertações, artigos e teses acerca do tema que vieram a fundamentar o desenvolvimento de indicadores. O projeto é embasado na adaptação da ferramenta Índice de Caminhabilidade (iCam), elaborada pelo Instituto de Pesquisas de Transporte e Desenvolvimento (ITDP) (ITDP Brasil, 2018) e na adição de indicadores agrupados em categorias (Tabela 1).

Tabela 1 - Categorias, atributos e indicadores utilizados na pesquisa

\begin{tabular}{|c|c|c|c|c|}
\hline Categorias & Atributos & Indicadores & $\begin{array}{l}\text { Adaptado do método } \\
\text { iCam }\end{array}$ & $\begin{array}{c}\text { Elaborado pelo Grupo } \\
\text { De pesquisa }\end{array}$ \\
\hline \multirow{9}{*}{ ( A ) Proteção e Segurança } & \multirow{2}{*}{ Segurança viária } & Travessias & $\bullet$ & \\
\hline & & Tipologia de rua & $\bullet$ & \\
\hline & \multirow{3}{*}{ Segurança pública } & $\begin{array}{c}\text { Levantamento Alterna tivo } \\
\text { para Iluminação }\end{array}$ & $\bullet$ & \\
\hline & & $\begin{array}{c}\text { Fluxo de Pedestres } \\
\text { Diurno e Noturno }\end{array}$ & $\bullet$ & \\
\hline & & Câmeras de segurança & & $\bullet$ \\
\hline & \multirow{4}{*}{ Proteção Física } & $\begin{array}{c}\text { Localização do es paço } \\
\text { para brincar }\end{array}$ & & $\bullet$ \\
\hline & & Material piso área infantil & & $\bullet$ \\
\hline & & $\begin{array}{c}\text { Material dos brinquedos } \\
\text { infantis }\end{array}$ & & $\bullet$ \\
\hline & & $\begin{array}{c}\text { Estado de conservação } \\
\text { dos brinquedos }\end{array}$ & & $\bullet$ \\
\hline \multirow{5}{*}{ (B) Conforto e imagem } & \multirow{4}{*}{ Ambiente } & Coleta de lixo & $\bullet$ & \\
\hline & & Polução sonora & $\bullet$ & \\
\hline & & Sombra e abrigo & $\bullet$ & \\
\hline & & \begin{tabular}{|c|}
$\begin{array}{c}\text { Sombra e abrigo em área } \\
\text { específica }\end{array}$ \\
\end{tabular} & & $\bullet$ \\
\hline & Mobiliário & Assentos & & $\bullet$ \\
\hline \multirow{5}{*}{ (C) Acessos e conexões } & \multirow[b]{2}{*}{ Mobilidade } & Dimensão das quadras & $\bullet$ & \\
\hline & & $\begin{array}{l}\text { Distância a pé ao } \\
\text { transporte público }\end{array}$ & $\bullet$ & \\
\hline & \multirow{3}{*}{ Calçada e pavimentação } & largura da calçada & $\bullet$ & \\
\hline & & Pavimentação da calçada & $\bullet$ & \\
\hline & & Pavimentação da praça & & $\bullet$ \\
\hline \multirow{10}{*}{$\begin{array}{c}\text { (D) Sociabilidade, usos e } \\
\text { atividades }\end{array}$} & \multirow{4}{*}{ Atra ção } & $\begin{array}{c}\text { Fachadas Fisicamente } \\
\text { Permeáveis }\end{array}$ & $\bullet$ & \\
\hline & & $\begin{array}{c}\text { Fachadas Visualmente } \\
\text { Ativas }\end{array}$ & $\bullet$ & \\
\hline & & Uso noturno e diurno & $\bullet$ & \\
\hline & & Uso misto & $\bullet$ & \\
\hline & \multirow{3}{*}{$\begin{array}{c}\text { Equipamentos e } \\
\text { atividades }\end{array}$} & $\begin{array}{c}\text { Equipamentos fixos e } \\
\text { serviços }\end{array}$ & & $\bullet$ \\
\hline & & $\begin{array}{l}\text { Atividades e } \\
\text { apropriações } \\
\text { comunitárias }\end{array}$ & & $\bullet$ \\
\hline & & $\begin{array}{c}\text { Atividades que incluem } \\
\text { os idosos }\end{array}$ & & $\bullet$ \\
\hline & \multirow{3}{*}{$\begin{array}{c}\text { estimulos sensorias e } \\
\text { motores }\end{array}$} & Estimulos motores & & $\bullet$ \\
\hline & & $\begin{array}{c}\text { Estimuo } \\
\text { sensorias/ludicos }\end{array}$ & & $\bullet$ \\
\hline & & Brincadeiras de regra & & $\bullet$ \\
\hline
\end{tabular}

Fonte: elaborado pelas as autoras (2019) com base no Icam (ITDP Brasil, 2018).

Esses foram organizados em grupos maiores chamados de atributos que por or sua vez foram divididos em quatro categorias que serão descritas a seguir, são elas: a) Proteção e Segurança; b) Conforto e imagem; c) Acessos e Conexões; e d) Sociabilidade, Usos e Atividades, de modo a avaliar a qualidade do espaço público destinados a idosos e crianças. 


\section{Categoria (a): Proteção e segurança}

Esta categoria busca referir sobre a seguridade da praça em três atributos principais, são eles: Segurança viária, Segurança públiça e Proteção física. Observa-se a velocidade das ruas de acesso; condições das travessias - faixa de pedestre, piso podotátil e sinalização; requisitos mínimos para a permanência de pessoas, além de uma boa iluminação. A proteção física do espaço de brincar também é observada nessa categoria, pois a localização; o material do piso; o material dos brinquedos e o estado de conservação afetam diretamente na segurança das crianças.

\section{Categoria (b): Conforto e Imagem}

Nesta categoria verifica-se a situação física do espaço da praça, dentro do atributo Ambiente que abrange os seguintes indicadores: coleta de lixo; polvição sonora; sombra e abrigo; e sombra e abrigo em área específica. Este último indicador refere-se como área específica o espaço da terceira idade e da infância, como mesa de jogos e playground.

Há ainda nesta categoria o atributo Mobiliário que analisa a oferta de assentos, visto que é uma das condições de conforto e permanência de pais e avós que acompanham as crianças no espaço público.

\section{Categoria (c): Acessos e Conexões}

As características como dimensões das quadras e distância a pé ao transporte público, situadas no atributo Mobilidade, destacam o deslocamento do pedestre, para percorrer a cidade e decidir qual caminho escolher para acessar ao espaço público. Além disso, essa categoria apresenta dois indicadores de pavimentação no atributo Calçada e Pavimentação, são eles: o perímetro da calçada e a parte interna da praça.

\section{Categoria (d): Sociabilidade, Usos e Atividades}

No atributo Atração, a relação da praça com a sua adjacência é avaliada quanto a presença ou não de interações por parte das edificações do entorno imediato, a partir dos seguintes indicadores: fachadas fisicamente permeáveis; fachadas visualmente ativas; uso noturno e diurno; e uso misto.

Outro atributo significativo para a categoria Sociabilidade, Usos e Atividades de pessoas é o Estímulos sensoriais e motores. Foi embasado na investigação do lúdico nos espaços públicos do município de São Carlos (SARTORI, ALVES E SOMMERHALDER, 2015). Os tipos de brinquedos direcionam as possibilidades de uso e brincadeiras, porém as crianças são conhecidas pela criatividade e imaginação fazendo com que criem objetos simbólicos e alterem a real função de um brinquedo, daí a relevância de averiguar a motivação sensorial e lúdica nos espaços.

A etapa de pontuação foi realizada adotando o próprio sistema de avaliação do iCam (ITDP Brasil 2018), no qual, obedecendo parâmetros pré-estipulados, pontua-se cada indicador com valores de 0 (zero) a 3 (três), como descrito no quadro abaixo (Tabela 2):

Tabela 2 - Pontuação para avaliação a partir de Indicadores

\begin{tabular}{|c|c|c|c|}
\hline Pontuação 3 & Pontuação 2 até 2,9 & Pontuação 1 até 1,9 & Pontuação 0 até 0,9 \\
\hline Ótimo & Bom & Suficiente & Insuficiente \\
\hline
\end{tabular}

Fonte: adaptado de Índice de Caminhabilidade, 2018 


\section{ANÁLISE DA PRAÇA ARGILANO DARIO}

Localizada no Estado do Espírito Santo, Vila Velha (ilustrada na figura 1), a Praça Argilano Dario, objeto deste estudo, situa-se no bairro Boa Vista II, na Regional Grande Centro, identificados na Figura 2.
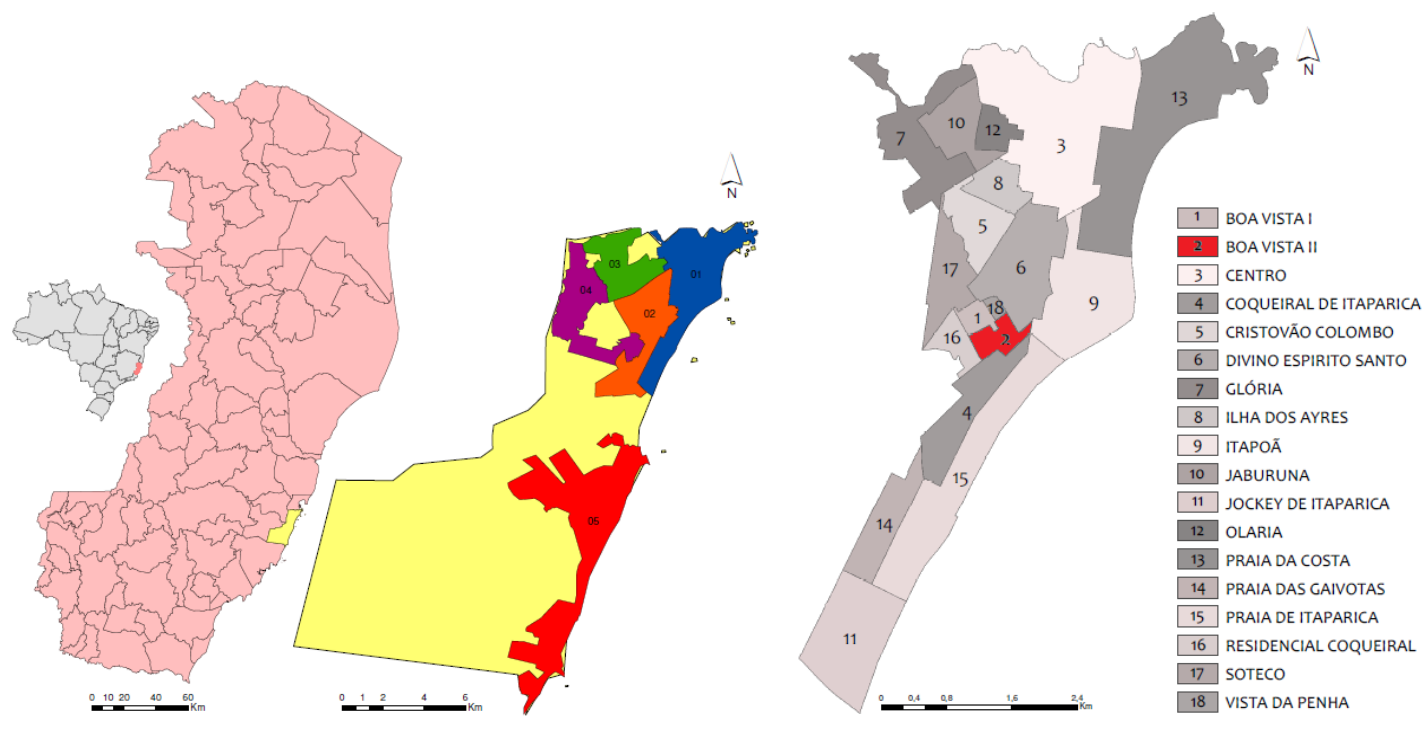

Figura 1 - Localização do estado do Espírito Santo, do município de Vila Velha (em amarelo), da Região Grande Centro (Azul) e do bairro Boa Vista II (Vermelho) Fonte: Elaborado pelo Grupo de Pesquisa "Paisagem urbana e Inclusão", 2018.
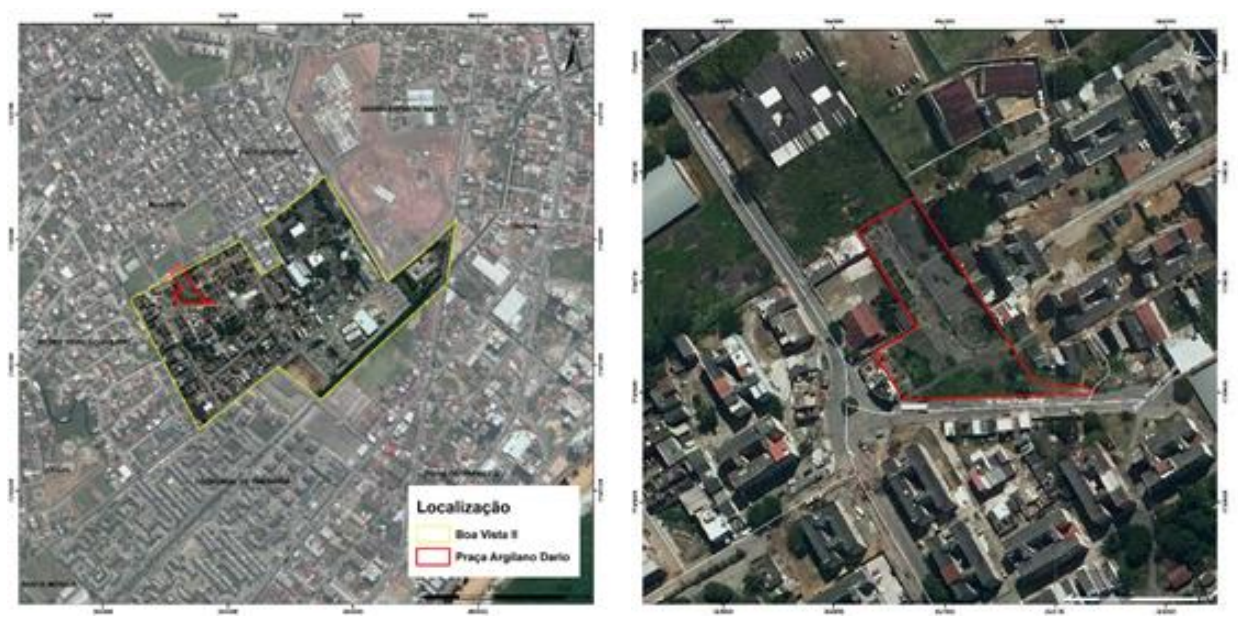

Figura 2 - Localização da praça no contexto do Bairro Boa Vista II. Fonte: Elaborado pelo Grupo de Pesquisa "Paisagem urbana e Inclusão", 2018.

Com aproximadamente 4.000 metros quadrados, a praça identificada como objeto de estudo, é caracterizada como o espaço público de maior abrangência em densidade populacional da Regional Grande Centro do município de Vila Velha, ou seja, possui o maior número de habitantes residindo dentro de um raio de 300 metros, constituindo-se, assim, um grande potencial de pessoas que podem valer-se desse espaço (RAMOS, JESUS, 2017).

Em relação aos aspectos físico-ambientais, a praça possui topografia acentuada e está situada abaixo do nível da rua, com cerca 7 (sete) metros de declive, fato este que estabelece uma barreira física e visual em relação ao seu entorno. O espaço é bem ventilado pois as construções ao redor são baixas, entretanto, o interior da praça é árido, com ausência de vegetação. 
A praça Argilano Dário indica carência de ações urbanísticas por parte do poder público, embora no ano de 2016 tenha passado por reformas, de responsabilidade do Shopping Vila Velha, em detrimento do Termo de Ajustamento de Conduta (TAC) firmado em dezembro de 2013. Porém, o projeto e a execução foram realizados sem a consulta prévia da população, não contemplando plenamente as necessidades locais, conforme expressam as figuras 4 e 5 abaixo.
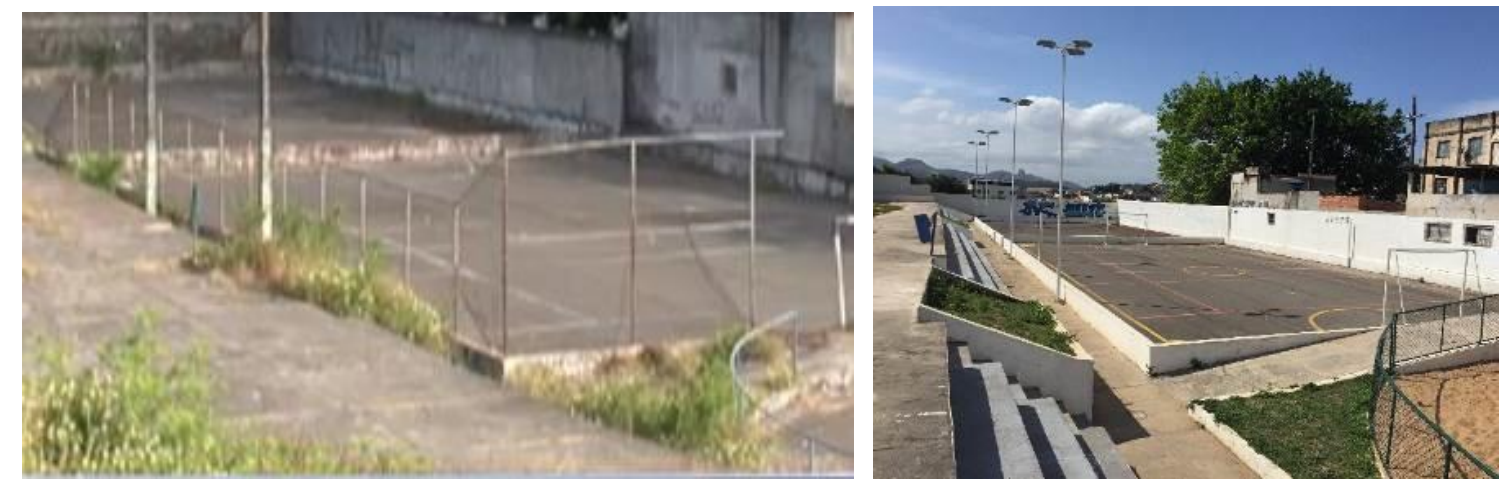

Figuras 4 e 5 - Imagens da praça Argilano Dário, antes

e após reforma em detrimento do TAC, em 2016

Fonte: Autoras, 2019

Para compreender melhor a análise da praça Argilano Dario, foi listado e detalhado a seguir as pontuações e seus motivos de acordo com cada categoria anteriormente explicada.

\subsection{Categoria (a): Proteção e segurança}

Nessa primeira categoria, a pontuação final recebeu nota suficiente. Os indicadores travessias, tipologia de rua, levantamento alternativa para iluminação e fluxos de pedestres diurno e noturno, receberam notas, entre suficiente e insuficiente. Foram observadas dificuldades em transitar no local, já que existem somente três formas de conexão com a praça e somente uma delas possui travessia de pedestre sinalizada - caracterizando o tipo de via com calçadas segregadas e velocidade inferior a $50 \mathrm{~km} / \mathrm{h}$. No indicador iluminação, percebe-se a ineficácia em relação ao tamanho da praça, sendo observado ainda uma grande parte da iluminação quebrada ou aparentemente queimada. $O$ fluxo de pessoas foi classificado como "suficiente", verificando baixo fluxo no período diurno e noturno tanto nos dias da semana quanto aos finais de semana - quesito pautado, também, em relatos pessoais foi evidenciado que a insegurança e falta de atratividade são os principais motivos pelo desinteresse na permanência no local.

Dentre os indicadores proposto pelo grupo de pesquisa, somente o indicador "Câmera de Segurança" recebeu nota insuficiente, já que não existiam aparelhos de monitoramento instaladas no local. O atributo proteção física, recebeu notas superior, já que foi registrado presença de área para brincar na praça. O espaço de brincar inserido está localizado no centro da praça e com cercamento, considerada a melhor situação. Possui ainda brinquedos em bom estado de conservação, entretanto, a variedade dos brinquedos limita os estímulos lúdicos e sensoriais das crianças já que são brinquedos tradicionais (Figuras 6 e 7). Soma-se ainda, o piso de areia que compromete o seu uso e possibilita a entrada de animais, tornando-o inseguro e insalubre. 

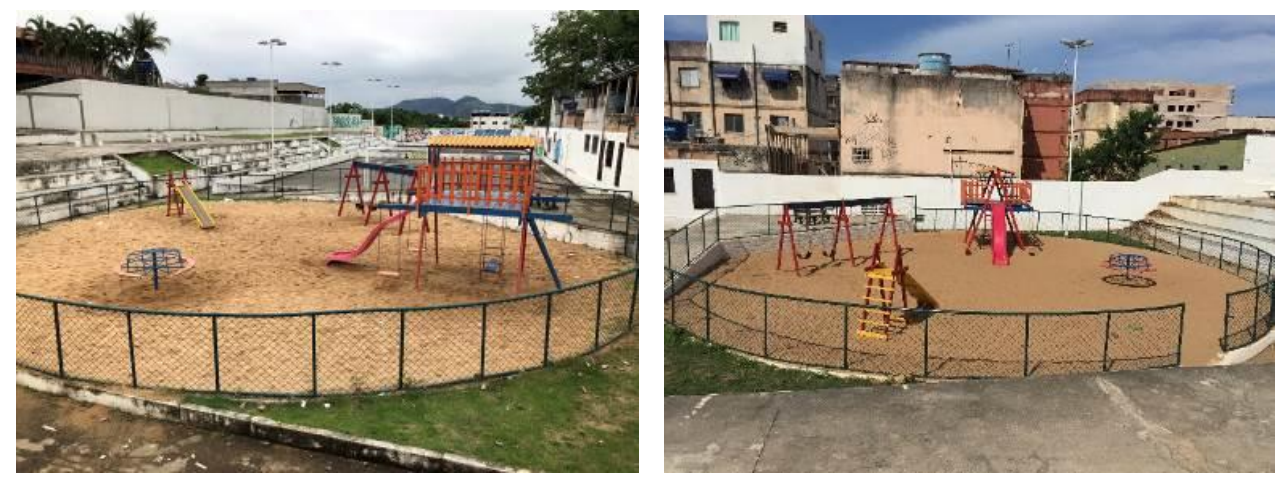

Figuras 6 e 7 - Imagens da área do playground em areia e cercado Fonte: Autoras, 2019

\subsection{Categoria (b): Conforto e Imagem}

A categoria conforto e imagem foi a categoria pior avaliada. Foi observado grande quantidade de lixo espalhado pelo recinto, tanto lixo domiciliar como descarte de móveis e embalagens. Percebe-se a ineficácia das arvores encontradas na praça, sendo muito afastadas, em pouco quantidade ou localizadas em locais que não produzem sombra no recinto.

Considerando a grande extensão territorial, a praça apresenta um número escasso de bancos, sobretudo ao redor do playground para pais e acompanhantes. Os poucos bancos existentes situam-se em área desprotegida de insolação, além de exibirem um design monótono e desinteressante, seguindo o modelo básico de banco de madeira plástica com encosto. Existe ainda uma quadra com arquibancada no recinto, duas mesas de jogos e alguns poucos bancos. Não foi encontrada acessibilidade no acessos e outras tipologias de bancos.

Nessa categoria somente polvição sonora e cobertura vegetal receberam nota boa já que foi observada que a praça é um local silencioso, devido a sua localização e baixo fluxo das vias do entorno. E quanto a cobertura vegetal, verificou-se, apesar de estar, de certa forma, abandonada, uma grande quantidade de espaços permeáveis na praça, como grama e vegetação plantada diretamente ao solo.

\subsection{Categoria (c): Acessos e Conexões}

Nessa categoria, somente $\mathrm{O}$ indicador de pavimentação da praça foi instituído pelo grupo de pesquisa, todos os outros são adaptações da ferramenta iCam. Sendo assim, somente a Dimensão das quadras recebeu nota insuficiente, pois as quadras no entorno das praças possuem extensão lateral com dimensão superior a 190 metros. O indicador 'distancia a pé ao transporte público' recebeu pontuação ótima já que existe um ponto de ônibus localizado do outro lado da rua, muito próximo à praça.

Percebeu-se que a Praça Argilano Dario, assim como a maioria das praças da Regional I, possuem calçadas regulares obedecendo a norma municipal, todavia a pavimentação interna permanece degradada, fazendo-se relevante analisar ambos os espaços. Sendo assim, os indicadores largura e pavimentação da calçada receberam pontuação considerada boas ( nota 2,0 ), onde foi verificado uma largura mínima maior que $1,5 \mathrm{~m}$ e que comporta o fluxo de pedestres da região e uma pavimentação por todo o trecho com menos de 5 buracos e/ou declives a cada 100m. Entretanto, a pavimentação 
no interior da praça recebeu nota 1 (um) pois forma registradas bastante irregularidades - menos que 10 buracos e desníveis a cada $200 \mathrm{~m}^{2}$ de praça.

\subsection{Categoria (d): Sociabilidade, Usos e Atividades}

A última categoria focou em avaliar os atrativos que a praça possui. No atributo 'Atração' foram utilizados somente critérios do iCam, sendo eles: fachadas fisicamente permeáveis, recebendo nota 3 (três) considerada ótima, já que, no entorno, as edificações possuem mais de 5 entradas por 100m de extensão. As fachadas visualmente ativas pontuaram nota 2 (dois) boa, tendo $40 \%$ da extensão da face ativa. Os indicadores de 'uso noturno' e 'uso misto' receberam nota 0 (zero), já que o uso noturno é baixo, existindo menos que 1 estabelecimento e mais que $85 \%$ dos edifícios é predominantemente de um tipo de uso, no caso, residencial.

Os outros indicadores, tanto do atributo de equipamentos e atividades e estímulos sensoriais e motores, foram propostos pelo grupo de pesquisa. No primeiro, os equipamentos físicos foram bem avaliados e receberam nota ótima, constando mais de 5 equipamentos/ serviços físicos - como: playground, quadra, mesa de jogos -, as atividades comunitárias receberam nota 2 (dois), onde consta duas apropriações acontecendo na praça, sendo elas: presença de barraquinhas - período noturno - e muro grafitado. As atividades que incluem idosos receberam nota 1 (um), constando somente uma apropriação - mesa de jogos - para idosos no recinto.

No atributo de 'estímulos sensoriais e motores', os indicadores de estímulos motores e brincadeira de regra receberam nota máxima - 3 (três) caracterizando, respectivamente, mais de 5 equipamentos que permitem atividades motoras - como pular correr, escorregar, balançar, girar -, e presença de quadra poliesportiva. Por fim, os estímulos sensorial e motor receberam nota 2 (dois), constando 3 possibilidades de estímulos na praça.

\section{CONSIDERAÇÕES FINAIS}

Os autores que abordam a temática analisam as formas de ocupação nos espaços destinados às crianças e idosos e mostram que a cidade deve buscar entender a importância da qualidade desses espaços e unir aspectos que são necessários para o reconhecimento de um espaço inclusivo que permite o convívio de todas as gerações.

A praça Argilano Dario possui grande potencial para ser um ponto de encontro dos residentes idosos e recintos de diversão para as crianças e familiares, todavia devido à falta de infraestrutura, acessibilidade e manutenção, está desprovida de vitalidade e subutilizada.

A vivência no local é mínima apesar de possuir mais de cinco equipamentos de lazer, tais como: playground, quadra descoberta, barras de manobra de skate, mesas de jogos e espaço para eventos. A maioria desses equipamentos não é de qualidade ou possui problemas como nenhuma área de sombra. Para a terceira idade, não é ofertada uma academia ao ar livre, o que é bastante solicitada pelos moradores.

Análise crítica apresentada nesse trabalha poderá auxiliar na produção de diretrizes para projeto de espaços mais inclusivos que contribuem para a vivência social e o desenvolvimento das habilidades especificas. 


\section{REFERÊNCIAS}

CORREA, Mariele Rodrigues. Envelhecer na cidade. Revista Espaço

Acadêmico. n. 184, p.35-46, setembro. 2016

GEHL, Jan. Cities for people. Washington: Island Press, 2010.

PFUTZENREUTER. Andrea Holz. Viver a Cidade, Envelhecer na Cidade. Os

Espaços Públicos como Interface para o Envelhecimento Pessoal. 2014, 157p.

Tese (doutorado em Arquitetura e Urbanismo) - Programa de pós-graduação

em Arquitetura e Urbanismo, Universidade Presbiteriana Mackenzie, São Paulo, 2014.

SARTORI, Gabriela Dias; ALVES, Fernando Donizete; SOMMERHALDER, Aline. A cultura lúdica infantil em parques públicos: Qual o espaço e tempo para brincar? Educação Unisinos. 19(3):401-408, setembro/dezembro 2015. 2015 Unisinos - doi: 10.4013/edu.2015.193.10. Disponível em:

<http://revistas.unisinos.br/index.php/educacao/article/view/6903> Acesso em: 17 ago. 2018.

RAMOS, Larissa A.; JESUS, Luciana N. Sistema de espaços livres de uso público: um estudo sobre o Grande Centro de Vila Velha. V!RUS, São Carlos, n. 14, 2017. Disponível em: <https://urbanidades.arq.br/2014/01/a-importancia-daparticipacao-popular> Acesso em: 28 jan. 2019 